\title{
A literatura
}

JOÃO ALEXANDRE BARBOSA

é professor aposentado da FFLCH-USP e autor, entre outros, de

A Biblioteca Imaginária (Ateliê Editorial).

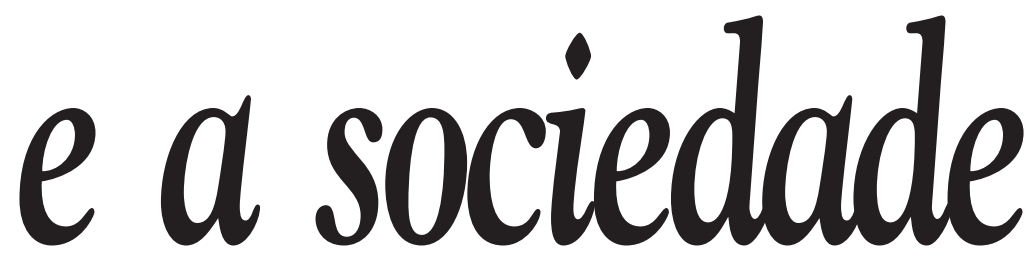

ada vez mais perto do século XXI, é natural que ocorram tentativas de balanço do século em que vamos vivendo e que, por outro lado, se procure vislumbrar aquilo que, de nossa época, passará para aquela que se aproxima.

É uma recorrência de todas as épocas: buscar a continuidade entre elas por intermédio de sínteses históricas que estabeleçam o domínio da memória sobre a fugacidade e apontem para a perenidade.

O tempo passa mas algo fica e este algo é a matéria da memória histórica que busca resgatá-lo para um presente que sempre é feito de passado e cujas marcas e imagens são inscrições para uma futura busca de decifração.

Por isso, a continuidade entre as épocas nunca é feita de diacronias absolutas: as rupturas que, em geral, apontam para o futuro fazem parte, mesmo no passado, daquelas inscrições que só o futuro virá decifrar. Mas não há passado sem uma intervenção do presente, e se o futuro do que passou é o nosso presente é porque a memória histórica, ela mesma, recusa o puro diacronismo e se afirma como presença sincrônica.

Sendo assim, somente aquelas sínteses que envolvem o presente situado do intérprete (para utilizar uma expressão já antiga de sabor sartriano) podem oferecer interesse: as demais são, em geral, jeremiadas, quando se referem ao passado, ou, no outro pólo temporal, vagos exercícios de futurologia.

Nesse sentido, quando se procura hoje dizer o que foi este século XX que vamos terminando - e o que ele foi é o resultado tanto daquilo que o precedeu quanto das projeções para os anos vindouros - melhor via, talvez, seja esboçar, a partir de um tema singular, o modo pelo qual este tema não apenas é apreendido pelo presente do intérprete mas como esta apreensão é antes o resultado de um movimento, cujas razões históricas e sociais são elementos definidores quer da linguagem da época, quer da própria metalinguagem com que o esboço é proposto, do que de uma volição pessoal do intérprete.

Desse modo, se tomarmos como fulcro 
de meditação o largo tema das relações entre literatura e sociedade, e não de uma aproximação particularizada a uma ou outra, veremos que, para início de conversa, seria impossível marcar o teor dessas relações sem que fosse levada em conta a própria transformação conceitual que sofreram os dois termos em decorrência do modo pelo qual quer literatura, quer sociedade passaram a designar aspectos diversos da realidade.

A pergunta pelo lugar que ocupam literatura e sociedade no conjunto das reflexões que possam ser feitas em fins do século XX envolve, por isso, não somente a questão mais ampla da própria representação da realidade, o que significa dizer modos de representação por onde as vinculações entre literatura e sociedade são extremadas, mas ainda a própria qualidade ou intensidade com que se dá tal representação. (Lembre-se, entre parênteses, que o rastreamento desse tema já foi abordado, de modo magistral, no livro Mimesis, de Erich Auerbach, publicado em 1942, e cujo subtítulo é expressamente "a representação da realidade na literatura ocidental".)
Éum tema aglutinador: desde os inícios das reflexões poéticas, desde, pelo menos, Platão e Aristóteles, a questão da representação é a contraparte teórica da própria operação poética. E não poderia ser de outra forma uma vez que, se instaurando no espaço ficcional, mas traduzindo elementos obtidos nas relações sociais, o poético tem a sua singularidade em operar intensamente nos intervalos entre a experiência e a representação da experiência pelos deslocamentos possíveis da linguagem.

Experiência, representação e linguagem: termos sem os quais não seria possível hoje, em fins do século, pensar tudo aquilo que foi realizado em nome da literatura e do poético ou das sociedades que viabilizaram as suas articulações. E isso porque, sobretudo, não se trata mais de falar em adequação entre literatura e sociedade como resultado de suas relações mas de incluir, como elemento fundamental de caracterização, quer da literatura, quer da sociedade, os momentos de inadequação através dos quais o poético se expande na criação de um espaço e de um tempo capa-

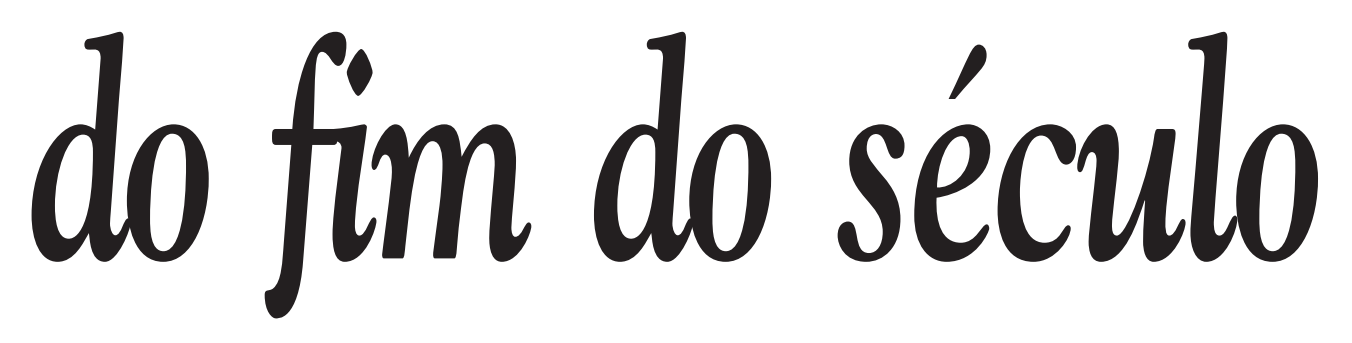


zes de romper com os estreitos limites de uma diacronia evolutiva de causa e efeito.

As conseqüências disso para as reflexões que preenchem os estudos literários são evidentes, indo desde as análises particularizadas das obras, em que os estímulos sociais são pensados na mais ampla integração estrutural que define a composição literária, até as leituras de história literária não mais pensadas como etapas de uma evolução unilateral mas como cortes sincrônicos operados numa ampla diacronia.

Por outro lado, as conseqüências referidas estão alicerçadas numa aguda sensibilidade para aquilo que um crítico fora de moda e de extração eliotiana, Lionel Trilling, chamou de "sentido do passado", isto é, uma certa intuição de que, mesmo nas obras as mais contemporâneas, estamos sempre lendo, ao lado das realizações formais que somente a contemporaneidade sabe decifrar, um substrato histórico que permite que a obra transcenda a sua própria existência temporal. Mas é uma transcendência paradoxal porque ela se firma, como já foi dito, numa presença sincrônica articuladora de diacronias.

Numa direção semelhante, a leitura das obras do passado, uma vez que se tenha escapado aos perigos do arqueologismo e do anacronismo - as duas principais ameaças que sempre rondam a leitura histórica -, somente se completa à medida que são preenchidos ou recuperados aqueles "acréscimos de significante", para usar uma expressão do crítico Frank Kermode, no ensaio The Classic, através dos quais a obra se transforma em nossa contemporânea. "Acréscimos de significante", e não apenas de significados, que permitem à leitura presente um sentido de continuidade para além do tempo de realização da obra, desde que, entre o espaço e o tempo da obra e sua atualização pelo leitor futuro, esteja a experiência de outras obras e de outras leituras-elementos isomórficos de outras realidades sociais.

Por isso, é possível dizer que a leitura atual de um clássico como o D. Quixote é a leitura da obra de Cervantes acrescentada por aquilo que, por exemplo, um Americo Castro leu na obra, mais a experiência de leituras diversificadas do leitor singular do Quixote, acrescidas das diferentes relações sociais e históricas que identificam este leitor.

Assim, toda a experiência histórica ou social do leitor contemporâneo, mais a leitura pontual de uma já extensíssima bibliografia cervantina, faz a diferença entre a sua percepção de Alonso Quijano e a daquele leitor que, ainda próximo das maravilhas das novelas de cavalaria, lia Cervantes no século XVII. (É claro que, mesmo num parêntese, não é possível deixar de mencionar, como ecos de uma crítica contemporânea de leituras de Cervantes, o memorável texto de Borges, "Pierre Menard, Autor del Quijote", de Ficciones, ou mesmo o não menos notável "Magias Parciales del Quijote", de Otras Inquisiciones.)

Mas essa insistência nas categorias de leitura e de leitor que vai dominando as minhas reflexões não pode e não deve ser escamoteada: pelo contrário, ela é reveladora de uma atitude com relação ao texto literário que encontra o seu respaldo nas próprias transformações que vêm sofrendo os modos de articulação entre experiência, representação e linguagem que são, por sua vez, os vetores principais das relações entre literatura e sociedade.

Na verdade, na leitura de uma obra há sempre uma pergunta de base tripartite que, embora não explicitada e nem sempre nesta ordem, corresponde àquelas articulações: que tipo de experiência se representa na obra por meio de tal ou qual linguagem?

Se num texto realista-naturalista a resposta pode ser tramada a partir das relações mais ou menos evidentes entre experiência e representação, através de uma linguagem que busca o seu próprio desaparecimento enquanto linguagem, no limite desejandose enquanto transparência para a revelação da própria experiência, como está, por exemplo, em Gustave Flaubert, para quem o ideal seria escrever uma obra sem assunto, que se sustentasse pela força do estilo, ou simplesmente desconhecendo outra função para a linguagem que não fosse a emi- 
nentemente representativa ou referencial, como está em Émile Zola, em textos posteriores, digamos os simbolistas e seus sucessores, a densidade de linguagem dificulta a apreensão das relações entre experiência e representação, na medida em que acrescenta àquelas a necessidade de uma, por assim dizer, consciência de leitura da literatura em que a experiência e sua representação parecem advir de uma realidade de segundo grau, produto já da ficção poética. E esta consciência, que, talvez, não seja mais do que uma intensificação daquela consciência literária de origens românticas, sobretudo anglo-germânicas, é dominante em grande parte da literatura pós-simbolista: uma consciência que se, por um lado, aponta para uma crise da representação, por outro, especifica a condição da literatura enquanto literatura e, como decorrência, do leitor enquanto leitor. Desse modo, a experiência que se representa é também, ou sobretudo, uma experiência de leitura.

Num outro contexto, Gaëtan Picon soube registrar o problema, escrevendo:

"O movimento poético que, partindo do Simbolismo do fim do século, conduz, através de múltiplas transformações, ao movimento surrealista, é uma consciência antes de ser uma criação. Nunca tantos escritos teóricos acompanharam o movimento da criação. A poesia contemporânea é uma poesia reflexiva, crítica, uma poesia de cultura, ligada à meditação e à leitura de obras anteriores" (1).

Mas foi, certamente, Paul Valéry, um dos herdeiros diretos do Simbolismo, que, em tex to de 1938, intitulado "Existence du Symbolisme", soube estabelecer a articulação precisa entre essa qualidade do estilo da nova poesia, para usar os termos de Picon, e suas relações com o público. Referindo-se aos simbolistas diz ele:

“Ils opèrent ainsi une sorte de révolution dans l'ordre des valeurs, puisqu'ils substituent progressivement à la notiondes oeuvres qui sollicitent le public, qui le prennent par ses habitudes ou par ses côtés faibles, celle des oeuvres qui créent leur public. Loin d'écrire pour satisfaire un désir ou un besoin préexistant, ils écrivent avec l'espoir de créer ce désir et ce besoin; et ils ne se refusent rien qui puisse rebuter ou choquer cent lecteurs, s'ils estiment par là conquérir un seul de qualité supérieure. C'est là dire qu'ils exigent une sorte de collaboration active des esprits, nouveauté très remarquable, et trait essentiel de notre Symbolisme. Peut-être ne serait-il impossible nifaux, de déduire de l'attitude de renoncement et de négation que j'ai dégagée tout à l'heure, d'abord ce changement dont je parle et qui consista à prendre pour partenaire de l'écrivain, pour lecteur, l'individu choisi par l'effort intellectuel dont il est capable; et ensuite, cette conséquence seconde, que l'on peut désormais offrir à ce lecteur laborieux et raffiné, des textes où ne manquent ni les difficultés, ni les effets insolites, ni les essais prosodiques et même graphiques qu'une tête hardie et inventive peut proposer de produire. La voie nouvelle est ouverte aux inventeurs. Par là, le Symbolisme se découvre comme une époque d'inventions, et le raisonnement très simple que je viens d'esquisser devant vous nous conduit, à partir d'une considération étrangère à l'esthétique, mais véritablement éthique, jusqu'au principe même de son activité technique, qui est la libre recherche, l'aventure absolue dans l'ordre de la création artistique aux risques et périls de ceux qui s'y livrent"' (2).

Vê-se como Paul Valéry é capaz de apreender a grande mudança nas relações entre literatura e sociedade, desencadeada peloque chama de revolução dos simbolistas.

Na primeira parte do texto, a tônica é precisamente o modo pelo qual os simbolistas criaram antes um público do que para um público, conferindo às experiências literárias o teor de uma necessidade, ou criação de uma necessidade, que passa, então, a ser exigida pelo leitor, bem na senda daquelas teorias das trocas mercadológicas elaboradas pela economia política de ori-
Cf. "Le Style de la Nouvelle Poésie", Histoire des Littératures, II, Encyclopédie de la Pléiade, Paris, NRF, 1957 p. 212.

Cf. "Existence du Symbolisme", in Paul Valéry, Ouevres, Paris, NRF, Bibliothèque de la Pléiade, 1957, pp. 69I-2. Eis uma tradução do texto: "Operam, assim, ma espécie de revolução na ordem dos valores, já que substituem progressivamente a noção das obras que solicitam o público, que o tomam por seus hábitos ou por seus pontos fracos, por aquela das bras que criam seu público. Longe de escrever para satisfazer um desejo ou uma necessidade preexistentes, escrevem com a esperança de criar esse desejo e essa necessidade; e nada recusam que possa repugnar ou chocar cem leitores se calcularem que, desse modo, conquistarão um único de qualidade superior.

Isso significa que exigem uma espécie de colaboração ativa dos espíritos, novidade muto importante e traço essencial de nosso Simbolismo. alvez não fosse impossíve ou falso deduzir da atitude de renúncia e de negação, que esclareci há pouco, primeiro essa mudança sobre a qua estou falando e que consistiu em tomar como parceiro do escritor, como leitor, o individuo escolhido pelo esforço intelectual de que é capaz; e em seguida, esta outra conseqüência: de hoje em diante, podem ser oferecidos esse leitor laborioso e refinado textos em que não faltam nem dificuldades, nem os efeitos insólitos, nem os ensaios prosódicos, e até gráficos, que uma cabeça ousada e inventiva pode se propor a produzir. O novo caminho está aberto aos inventores. Neste, o Simbolismo descobrese como uma época de invenções; e o raciocínio bem simples que acabo de esboçar diante de vocês nos leva, a partir de uma consideração alheia à estética, mas verdadeiramente ética, até o próprio princípio de sua atividade técnica, que é a livre procura, a aventura absoluta na ordem da criação artística dos riscos e perigos daqueles que ela se entregam" (in Paul Valéry, Variedades, organização e introdução de João Alexandre Barbosa, tradução de Maiza Martins de Siqueira, São Paulo, lluminuras, 1991). 
gem marxista; na segunda parte, o argumento central gira em torno da interação entre autor e leitor, em que este último assume uma posição de grande atividade na circulação da obra: o leitor não mais apenas como recipiente da obra produzida pelo autor mas um parceiro do escritor, como diz Valéry. E, por isso, capaz de seguir, e mesmo solicitar, as inovações inventivas e mesmo caprichosas das cabeças mais ousadas. Uma ética da leitura, portanto, que não despreza o estágio técnico, como lembra o próprio Valéry nas últimas frases do texto.

Este ensaio de Valéry foi escrito às vésperas da Segunda Guerra Mundial quando as realizações do Simbolismo já se haviam transformado em moeda corrente da literatura e das artes, e a revolução, por ele anotada no início do texto, havia sido responsável por todas aquelas pesquisas que, entre as últimas décadas do século XIX e as primeiras do XX, seriam a base dos vários movimentos de vanguarda (Expressionismo, Cubismo, Futurismo, Dadaísmo, etc.), via aberta das invenções, como também anota Valéry, que puseram em xeque os esquemas naturalistas e positivistas com que a crítica de então buscava estabelecer as relações entre literatura, sociedade e história.

Mas entre a existência do Simbolismo, tal como ele foi pensado e praticado entre os anos 70 e 90 do século XIX e os inícios da Segunda Guerra Mundial, a sociedade já se defrontara com o primeiro conflito de âmbito mundial, a Grande Guerra de 191418 , a partir da qual, mais precisamente no ensaio com que abre o primeiro volume de Variété, de 1924, "La Crise de 1'Esprit", que é de 1919, podia Valéry registrar a sensibilidade para o grande desastre a que havia chegado a civilização européia, escrevendo de modo lapidar:

"Nous autres, civilisations, nous savons maintenant que nous sommes mortelles.

Nous avions entendu parler de mondes disparus tout entiers, d'empires coulés à pic avec tous leurs hommes et tous leurs engins; descendus au fond inexplorable des siècles avec leurs dieux et leurs lois, les académies et leurs sciences pures et appliquées, avec leurs grammaires, leurs dictionnaires, leurs classiques, leurs romantiques et leurs symbolistes, leurs critiques et les critiques de leurs critiques. Nous savions bien que toute la terre apparente estfaite de cendres, que la cendre signifie quelque chose. Nous apercevions à travers l'épaisseur de l'histoire, les fantômes d'immenses navires qui furent chargés de richesse et d'esprit. Nous ne pouvions pas les compter. Mais ces naufrages, après tout, n'étaient pas notre affaire.

Élam, Ninive, Babylone étaient de beaux noms vagues, et la ruine totale de ces mondes avait aussi peu de signification pour nous que leur existence même. Mais France, Angleterre, Russie... ce seraient aussi de beaux noms. Lusitania aussi est un beau nom. Et nous voyons maintenant que l'abime de l'histoire est assez grand pour tout le monde. Nous sentons qu'une civilisation a la même fragilité qu'une vie. Les circonstances qui enverraient les ouvres de Keats et celles de Baudelaire rejoindre les oeuvres de Ménandre ne sont plus du tout inconcevables: elles sont dans les journaux" (3).

A representação dessa sensibilidade para um mundo destroçado, cujos fragmentos dinamitaram a paz e o conforto da belle époque européia, seria a tarefa ingrata para aqueles escritores que, embora nascidos ou formados sob a égide da crise de representação percebida, mas também cultuada, pelos simbolistas, não mais se sentiam confortáveis ou pacificados e que, portanto, se defrontavam com uma dupla tarefa: a de representar, mas incluindo na representação a crítica de sua própria crise.

E os caminhos escolhidos por cada um serão os mais diversos: desde o desvio simbolista de um T. S. Eliot, na composição de um poema em mosaico, como The Waste Land, em que as alusões a literaturas dos mais diferentes lugares e épocas são passadas pelo tom menor da herança simbolista de um Laforgue ou de um Corbière, sem 
esquecer o tom elevado, mas irônico, de um Baudelaire, que vem literalmente citado no último verso da primeira estrofe, tudo estaqueado por sobre os seus próprios fragmentos, como está dito num dos últimos versos do poema, até a utilização de um alemão solene e de cadências goethianas, como está no Thomas Mann de A Montanha Mágica ou, sobretudo, do Doutor Fausto, ou ainda na admirável prosa, de longos e remansosos parágrafos, do Hermann Broch de A Morte de Virgílio, ou a prosa ácida e de redução de um Kafka, conferindo a seu alemão os sombrios desvãos de uma experiência judaica das circunstâncias particulares de uma Europa Central, no entanto marginalizada pelos avanços guerreiros dos capitalismos das grandes potências de uma outra Europa. Ou mesmo o caso notável de um James Joyce, dando um sentido épico aos destroços do Império Britânico a partir de uma leitura irlandesa daquele império, mas convocando para aquela leitura a tradição mais nobre da herança cultural européia, estabelecendo uma dependência, quase sem precedentes na história literária, entre experiência, representação e linguagem de tal maneira que nas páginas do Ullysses o leitor encontre o máximo de intervenção na linguagem e uma representação da realidade tão intensa que seria difícil, ou mesmo impossível, marcar onde começa uma e termina a outra, na medida em que a experiência pessoal e coletiva é, sobretudo, uma experiência de leitura desde a cultura grega até os livros de ficção popular (os pennybooks) da gíria londrina dos caminhos e descaminhos dos Blooms.

Estas e muitas outras obras apontam para aquilo que o crítico norte americano R. P. Blackmur, em ensaio de 1948, chamava de a burdenfor critics que traduziríamos aproximadamente por um fardo para os críticos, is to é, segundo o crítico, como passar da grande tônica conferida à representação de uma sociedade que é, já por si mesma, um fardo para a experiência dos autores, para a apreensão daquilo que é o próprio ato de criação literária, ou seja, a instauração de um espaço ficcional por intermédio da linguagem que, por sua vez, responde à beleza e ao mais completo sentido da obra literária. Esta parecia ao então new critic, e apenas encerrada há três anos a Segunda Guerra Mundial, o trabalho crítico essencial: um ato performativo capaz de revelar a bela complexidade da literatura. Diz ele:

"The beauty ofliterature is that it is exigent in the mind and will not only stand still but indeed never comes fully into its life of symbolic action until criticism has taken up the burden of bringing it into performance and finding its relation to the momentum of the whole enterprise" (4).

É claro que esta tarefa não é invenção da experiência moderna ou contemporânea da literatura: em todas as épocas, os leitores ou espectadores foram chamados a intervir na realização plena das obras, e as observações de Blackmur se referem precisamente à intensidade das intervenções que a crítica é chamada a exercer. Mas a questão está em como se há de pensar numa intervenção, ou numa performance, para usar a terminologia de Blackmur, que conserve a tensão entre o teor de representação - a essência do fardo - e seu modo de articulação poética. Mais ainda quando se vive uma época em que a própria viabilidade da representação entra em crise por força das transformações históricas e sociais que terminaram por caracterizar a nossa comouma era de suspeita, para utilizar os termos de um ensaio famoso de Nathalie Sarraute (5).

Embora pensado e escrito sob o fogo cruzado das propostas radicais do Nouveau Roman, o ensaio tinha o mérito de ampliar o seu alcance para uma reflexão mais abrangente, acrescentando elementos essenciais para uma reflexão acerca da tarefa da crítica diante de uma literatura que parecia caminhar para a sua própria destruição, como vigorosamente afirmava Maurice Blanchot, em artigo publicado nos anos 60, na Nouvelle Revue Française em que se perguntava pelo destino da literatura ("Où va la littérature? La littérature va envers ellemême, c'est-à-dire, envers sadestruction").

Era o mesmo Blanchot que, numa de
4 Cf. "A Burden for Critics", in Lectures in Criticism, The Johns Hopkins University, Introduction by Huntington Cairns, New York, Pantheo Books (Bollingen Series XVI), 1949. Eis uma tradução do texto: "A beleza da literatur é que ela é exigente na mente e não somente permanece estática mas, de fato, nunca realiza completamente sua vida de ação simbólica ate que a crítica assuma o fardo de performá-la e encontra suas relações com o momento de todo o conjunto".

5 Nathalie Sarraute, L'Ère du Soupçon, Essais surle Roman, Paris, Gallimard, 1956. 
suas colaborações para a mesma Nouvelle Revue Française, de maio de 1960, chamava a atenção para a singularidade anti-retórica da obra de Albert Camus, exercendose, como pensava o crítico, no sentido de um desvio para a simplicidade, título de sua crônica, em que os traços de estilo eram, por assim dizer, rasurados pelo peso concedido à representação agônica de um mundo despedaçado pela tensão entre o indivíduo e as circunstâncias absurdas da história e da sociedade.

Todas essas reflexões realizadas nos anos 50 e 60 que, de certa forma, se juntavam àquelas dos anos 40 e 50 do New Criticism, deságuam nos vários textos que vão compor a Nouvelle Critique francesa, cujo principal traço seria precisamente fazer convergir a análise particularizada das obras, pelo uso de uma lente, por assim dizer, de aproximação lingüística, e uma leitura das estruturas míticas, sociais e históricas da representação literária.

Mais do que uma convergência: uma leitura da obra literária em que se buscava manter a tensão entre aquele fardo da representação descrito por Blackmur e a própria composição literária. Oque significava apontar para uma percepção dos elementos sociais e históricos que configuram a obra em seus momentos de formalização, quer dizer, enquanto integradores de uma morfologia através da qual a obra é definida.

Por isso, no plano das teorizações sobre a história literária, o principal alvo dos nouveaux critiques é Gustave Lanson, cuja Histoire de la Littérature Française havia sido publicada em 1894, cujas edições sucessivas fizeram dela o paradigma, por excelência, da crítica histórica em que se articulavam as heranças naturalistas e positivistas do século XIX e um certo humanismo crítico, de laivos impressionistas, embora fazendo a defesa do rigor histórico e da objetividade filológica. Sobre essa articulação, sob a qual ele via passar de contrabando (o termo é dele mesmo) uma ideologia conservadora de domínio do saber, Roland Barthes escreveu o polêmico texto Sur Racine, buscando libertar o grande poeta trágico das interpretações cristalizadas dos vários e sucessivos naturalismos críticos capazes de falar de sua obra sem, em nenhum momento, repensar a sua significação, para a literatura francesa, enquanto poeta e não apenas enquanto monumento daquela literatura que, por sua vez, operara a cristalização de certas ideologias dominantes no século XVII francês.

$\mathrm{Na}$ verdade, um ano antes da publicação da Histoire, em 1893, Gustave Lanson publicara um ensaio sobre Mallarmé através do qual é possível ver como ele estava aprisionado ao paradigma crítico de seu tempo, aquele cujas linhas mestras eram ainda as do naturalismo e do positivismo que privilegiavam a referencialidade.

A acusação de ininteligibilidade que faz à obra de Mallarmé, como se lerá em seguida, respondia à prevalência, naquela poesia, do princípio de construção sobre o da representação que, por então, problematizava as abordagens crítica e histórico-literária fundadas naquelas linhas. Eis um trecho substancial do ensaio:

"Ele [Mallarmé] dá por objetivo da arte realizar o irreal, exprimir o inexprimível, comunicar o incomunicável. Seja; admito esta ambição; de fato, não existe sem isso grande poesia, nem arte elevada. Mas a impossibilidade manifesta-se quando se olham os meios que ele pretende empregar. Ele quer desvencilhar-se de formas reais, signos expressivos, valores comunicativos: em outros termos, quer apreender o ininteligível e transmiti-lo sem o ter convertido de algum modo em inteligível. É esquecer a condição, a miséria, se se quiser, de nossa humanidade, fadada por seus pecados aos atos distintos da inteligência. Nós não atingimos diretamente pelo espírito qualquer realidade, nem sensível, nem espiritual, nem finita, nem infinita. Não podemos senão usar um desvio, substituir as realidades por signos inteligíveis, por símbolos suscetíveis de demonstração. A ciência existe a este preço e a arte não tem uma outra lei. Criação da inteligência, como a ciência, não pode ser outra coisa senão intelectual e se, às vezes, aspira a dar a sensação, a comunicação do ininteligível, 
fá-lo por intermédio de signos e de relações que exprimem inteligivelmente o caráter ininteligível. Aqueles que conhecem Pascal sabem bem o que quero dizer. O Sr. Mallarmé, querendo usar signos inteligíveis fazendo abstração de seu valor de signos inteligíveis e querendo formar símbolos irreais e infinitos que manifestem diretamente o eu essencial e o ideal infinito, põe-se em contradição com as condições próprias da arte" (6).

O que é esta inteligibilidade tão acirradamente defendida por Lanson que, logo em seguida, ele traduzirá também por clareza de idéias, numa réplica evidente ao famoso dito de Mallarmé (“" [...] que se entenda que a obra literária, fazendo-se com palavras, faz-se com idéias[...] entre uma idéia clara e uma idéia confusa, é a idéia clara que, mostrando mais, contém mais, e que é o grau superior da idéia"), o que é esta inteligibilidade senão a vitória da representação sobre a construção, sem que se passe por aqueles estágios decisivos da própria poíesis que identifica o texto artístico?

Esta, de fato, vai ser a grande tarefa da crítica e da história literária que surgem a partir dos anos 60: sem desprezar o fardo da representação, para o qual está convocada toda a obra que pretenda ultrapassar a tendência ao solipsismo dos novos tempos, instaurar um espaço de reflexão capaz de insinuar o modo pelo qual o social e o histórico passam a ser percebidos como elementos interiorizados pelas tensões construtivas do texto artístico.

Para isso, foram importantes tanto as heranças do close reading apreendidas a partir das experiências de leitura do New Criticism anglo-americano, quanto as análises estilísticas e filológicas da Estilística alemã ou espanhola, como ainda as novas pesquisas do Estruturalismo de origens antropológicas, marcadamente francês, ou mesmo a redescoberta das teses formalistas e estruturalistas do Formalismo Russo ou do Estruturalismo Tcheco. O que, diga-se de modo complementar, seria explicitado pelas teses avançadas por aqueles teóricos da crítica e da história literária que passa- ram a pensar na leitura e no leitor como ângulos privilegiados de um processo de sutura entre forma e história, tais como eles eram discutidos em ensaios da chamada Estética da Recepção e do Efeito.

É claro que estas aproximações, reivindicando a qualidade artística da obra literária, muitas vezes parecem, em seus piores momentos, fazer inclinar a leitura para uma espécie aguda de formalismo, sem que as tensões entre formalização e representação sejam preservadas. Mas são exemplos, por assim dizer, caricaturais a que a própria integridade da obra artística termina por oferecer resistência. E a melhor demonstração está nas mais recentes leituras do chamado Desconstrucionismo por onde se pode vislumbrar o peso concedido ao esforço desenvolvido por alguns críticos tais como Paul de Mann, Miller, Hartmann ou Bloom - em fazer integrar a uma leitura que suspende a procura do sentido os despojos de uma história enclausurada nos índices filológicos dos textos.

Mais do que uma negação da história, tais leituras (enquanto são marcadas por um tempo e uma paciência que somente o verbo inglês peruse parece ser capaz de traduzir, significando ler cuidadosamente) pretendem rasurar a distância entre o leitor e o objeto lido, tornando também aquele um objeto que se lê - e sua história pessoal e coletiva - no próprio ato de ler o objeto. De tal maneira que é precisamente no seio do movimento de desconstrução que se vai encontrar novas maneiras de uma defesa da filologia, como está em Paul de Mann, por exemplo, que até parece reviver os antigos argumentos de Servais Etienne no já clássico Défense de la Philologie (7).

Por outro lado, se o peso concedido à representação, sem o necessário aporte crítico-filológico, transforma a reflexão crítico-histórica numa via de mão única, amolecendo a tensão entre fazer e dizer, que é o texto artístico, ele foi, sem dúvida, responsável pela incorporação à literatura dos grandes temas sociais e históricos que vêm dominando a cena mundial, assim como a abertura do cânone literário para aquelas literaturas marginalizadas por aqueles mes-
6 Cf. "Stephane Mallarmé", in Essais de Méthode de Critique et d'Histoire Littéraire, Rassemblés et présentés par Henri Peyre, Paris, Hachete 1965, p. 474

Cf. Servais Etienne, Défense de la Philologie et Autres Écrits, Paris, La Renaissance du Livre, 1965 . Trata-se da reedição do livro de 1933 publicado em Liège. Quanto a Paul de Mann, leia-se, por exemplo, o ensaio "The Return to Philology", hoje fazendo parte do volume The Resistence to Theory (Minneapolis, University of Minnesota Press, 1986) 
Na página

seguinte, gravura

de Gustave Dürer

para o livro de

Cervantes
8 Refiro-me, sobretudo, a Formação da Literatura Brasileira. Momentos Decisivos, São Paulo, Livraria Martins Editora 1959. mos temas quando tratados pelas nações que concentram o poder político e o poder do saber.

Nesse sentido, a renovação do cânone da literatura ocidental, com a entrada à consideração de temas relacionados a gêneros e etnias minoritárias, embora ainda percebidos, em sua grande maioria, dentro dos parâmetros de uma crítica naturalista tardia, às vezes travestida de um marxismo requentado, é, talvez, o acontecimento mais relevante da crítica, em suas relações com a sociedade e a história, de fins do século.

Foi o caso, por exemplo, da decisiva incorporação à literatura mundial das literaturas ibéricas da América, sobretudo as de língua espanhola, mas preparando o caminho para alguns textos em língua portuguesa do Brasil, no bojo daqueles movimentos de libertação que agitaram os países colonizados pela Europa entre os anos 50 e 60 .

É importante observar que as obras agora recolhidas pela abertura do cânone, se, em grande parte, respondiam a um viés político e social, traziam, não obstante, as marcas das tensões entre representação e formalização literária, fosse por terem as suas origens numa crítica interna aos grandes movimentos literários da vanguarda histórica européia (e foi o caso do Surrealismo, tal como ele foi repensado na obra de um Octavio Paz, de um Julio Cortázar, de um Alejo Carpentier, de um Lezama Lima, de um García Márquez ou do poeta brasileiro João Cabral de Melo Neto), fosse por afirmarem a singularidade de uma voz que, a partir do continente latino-americano, interiorizava a crítica das articulações entre tradição e modernidade, um dos grandes topos da crítica histórica européia, tal como ocorria na obra de um Jorge Luís Borges, na Argentina, ou de um João Guimarães Rosa, no Brasil.

É claro que a tais obras respondiam os ensaios crítico-históricos, não apenas surgindo como decorrência do teor inventivo daquelas, mas, em alguns casos excepcionais, antecipando o tipo de relações que aquelas obras seriam forçadas a manter com a complexidade da vida social e de sua es- trutura histórica, como foi o caso, para dar um só exemplo, que conheço melhor, do ensaísmo crítico-histórico de Antonio Candido no Brasil (8).

Sendo assim, é possível dizer que a própria conceituação de sociedade que interessa à reflexão sobre a literatura sofre uma transformação de base, à medida que se intensifica a noção fundamental, a que já anteriormente acenei, de que não se trata mais de investigar relações de adequação entre literatura e sociedade, mas de fazer operacional, para a crítica das obras artísticas, os momentos de inadequação, sobretudo em países em que as pressões de ordem histórica, política e econômica impossibilitam qualquer leitura de causa e efeito na ordem intelectual e artística.

Por isso mesmo, será uma constante crítico-histórica, nesses países, a vinculação entre os movimentos de vanguarda e as leituras historicizadas do texto literário, manifestando-se através de revisões e resgates de obras e autores para os quais o futuroé, então, determinado por uma espécie de leitura anacrônica ou, melhor dizendo, sincrônica se referida ao presente situado do leitor.

De qualquer modo, uma leitura inexoravelmente histórica. Mas uma história que não elide a poeticidade porque sabe que a sua é uma natureza, sobretudo, discursiva e, portanto, informada por todas as ambigüidades do discurso. Não uma história de datas, fatos e personagens, mas aquela que põe sob suspeita, para voltar aos termos de Nathalie Sarraute, a própria capacidade de sua representação.

No caso estrito da literatura, não uma história da poética mas uma poética da história em que o analista, o estudioso, o crítico, ou seja lá qual for o seu nome, existe, antes de mais nada, num intervalo de tensões entre a realidade e a linguagem de sua representação. A leitura desse intervalo é uma leitura insegura, instável, sempre en abîme: mas que literatura e sociedade que valham a pena ser consideradas são totalmente seguras, estáveis, sem sobressaltos abismais? Talvez as totalitárias e dessas não quero tratar. 
